\title{
A QUANTITATIVE STUDY OF THE EFFECT OF ISCHAEMIA ON THE GERMINAL EPITHELIUM OF RAT TESTES
}

\author{
D. Y. TJIOE* AND E. STEINBERGER \\ Division of Endocrinology and Reproduction, Research Laboratories, \\ Albert Einstein Medical Center, Philadelphia, Pa. 19141
}

(Received 24th February 1969)

\begin{abstract}
Summary. A quantitative analysis of the germinal epithelium cells in rat testes rendered ischaemic for a period of $100 \mathrm{~min}$ was performed. This period of ischaemia produces a reversible damage to the process of spermatogenesis.

Analysis of the testes at 2-, 7-, 14- and 28-day intervals after ischaemia, revealed damage to type A spermatogonia in stages XII and XIV, intermediate type A spermatogonia, type $B$ spermatogonia and resting primary spermatocytes. The decrease in numbers, or absence of other cell types at the various time intervals after ischaemia was shown to be due to a maturation depletion process. In view of the fact that only cells undergoing mitosis or in the DNA-synthesizing period of meiosis were affected, it is suggested that germinal epithelium cells are most susceptible to ischaemia during this DNA-synthesis period.
\end{abstract}

\section{INTRODUCTION}

The first systematic and extensive study of the effect of ischaemia on the mammalian testes was published by Oettlé \& Harrison (1952). Utilizing the recently gained knowledge of the dynamics of spermatogenesis, Steinberger \& Tjioe (1969) re-evaluated the effect of ischaemia on rat testes and suggested, on the basis of the histological data, that ischaemia produces damage to specific cell types in the germinal epithelium.

Application of quantitative methods of germinal epithelium analysis permits precise localization of the damage (Steinberger, 1962). The aim of this study was to extend previous qualitative observations and to pinpoint the site of damage produced by ischaemia in the seminiferous epithelium of rat testes.

It has been demonstrated that ischaemia of 120 min duration, or longer, causes non-specific damage to the germinal epithelium expressed by generalized degeneration of all cell types. Ischaemia of less than $100 \mathrm{~min}$ produces definite and selective damage to the germinal epithelium. Ischaemia of less than $60 \mathrm{~min}$

* Present address: University of Indonesia Medical School, Department of Biological Sciences, Salemba 6, Djakarta, Indonesia. 
duration does not produce detectable damage (Steinberger \& Tjioe, 1969). In view of these observations, ischaemia of $100 \mathrm{~min}$ duration was selected for this study.

\section{MATERIALS AND METHODS}

Adult rats (300 to $350 \mathrm{~g}$ ) of the Long-Evans strain bred in our laboratories were used in this study. The testicular artery was occluded for a period of $100 \mathrm{~min}$, according to the method of Oettle \& Harrison (1952), as described previously (Steinberger \& Tjioe, 1969). Groups of animals were killed at 2-, 7-, 14- and 28-day intervals after the episode of ischaemia. The testes were immediately fixed in Bouin's solution and processed by the conventional histological techniques. The tissues were cut at $4 \mu$ and stained with PAS-iron haematoxylin.

The technique employed for the quantitative analysis of seminiferous epithelium has been described in the past (Steinberger, 1962). In brief, histological preparations of testicular sections were photographed. Each tubule was numbered on the photograph and identified in the specimen under the microscope. The stage of spermatogenesis was determined in each tubule, all germinal cells were identified and counted. No attempt was made to correct the counts for cell size, as the primary interest concerned a comparison with normal controls, not with the mechanism of spermatogenesis as such. Excluded from the counting were the mitotic and meiotic figures, secondary spermatocytes and spermatids in steps 9 to 19 .

\section{RESULTS}

The frequency distribution of the stages of the cycle of seminiferous epithelium after 100 min occlusion of the testicular artery

No change in frequency distribution was observed, except in stages III and XIII, in the 28 -day animal group. Since spermatids were markedly depleted at this time interval and since identification of these stages is greatly dependent on details of the morphology of the spermatids, this decrease may be an artifact. If this is considered as an artifact, then ischaemia produces no changes in the frequency distribution of the stages of the cycle of seminiferous epithelium.

\section{Counts of germinal epithelium cells following ischaemia}

Spermatogonia. The data are presented in Table 1. They are expressed as arithmetic means of the counts \pm one standard deviation. Two days after ischaemia, there was a significant decrease in the number of type A spermatogonia in stage XIV, type A and intermediate spermatogonia in stage $I$, intermediate type spermatogonia in stages II, III and IV and type B spermatogonia in stage V. At 7 days, a significant decrease of type B spermatogonia in stage VI and a return to normal of spermatogonia in stages XIV and $I$ to $V$ was observed. There were no changes in the number of spermatogonia in the 14and 28-day groups after the ischaemia, showing that the effect of ischaemia was very short-lived and that the stem cells must have started re-population rapidly. 


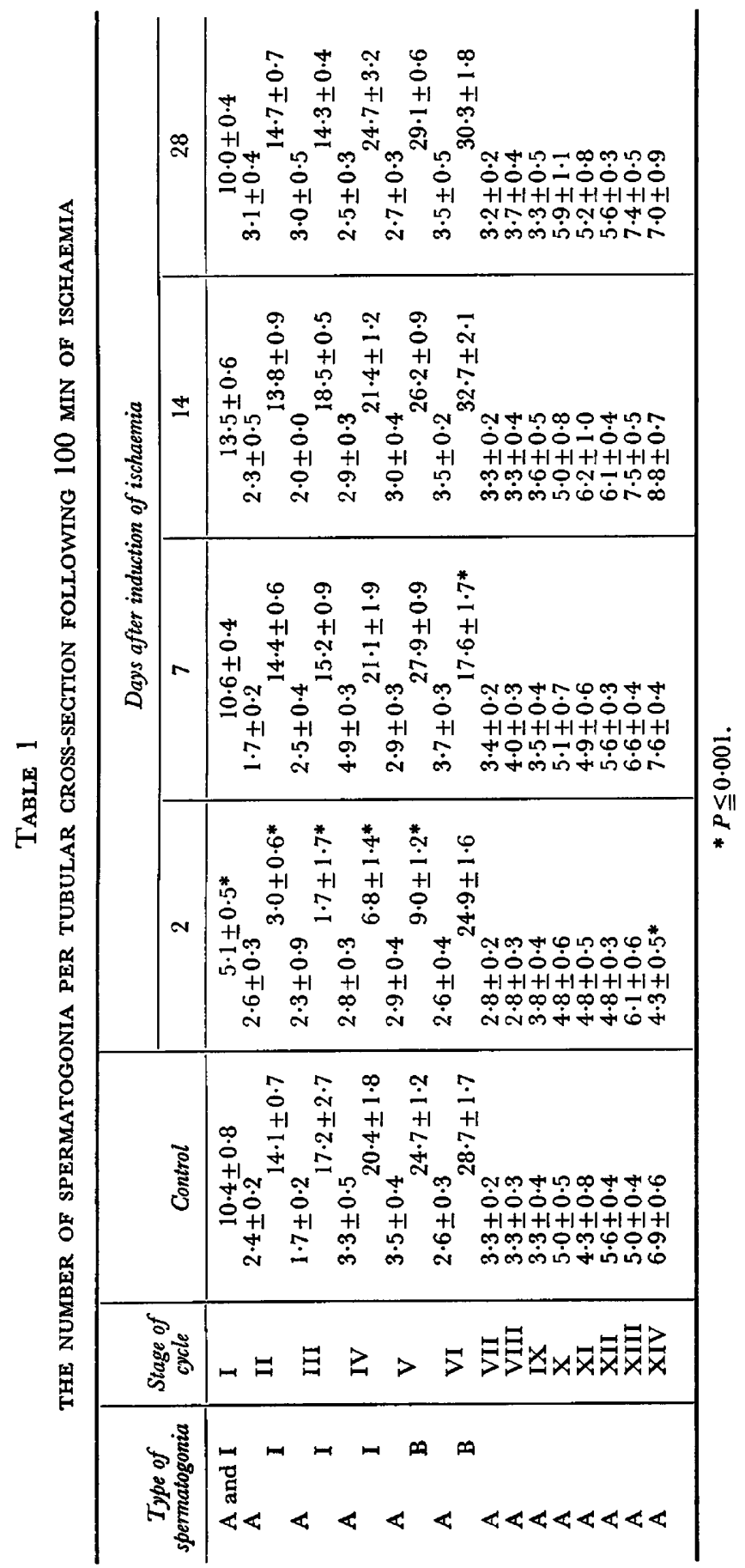




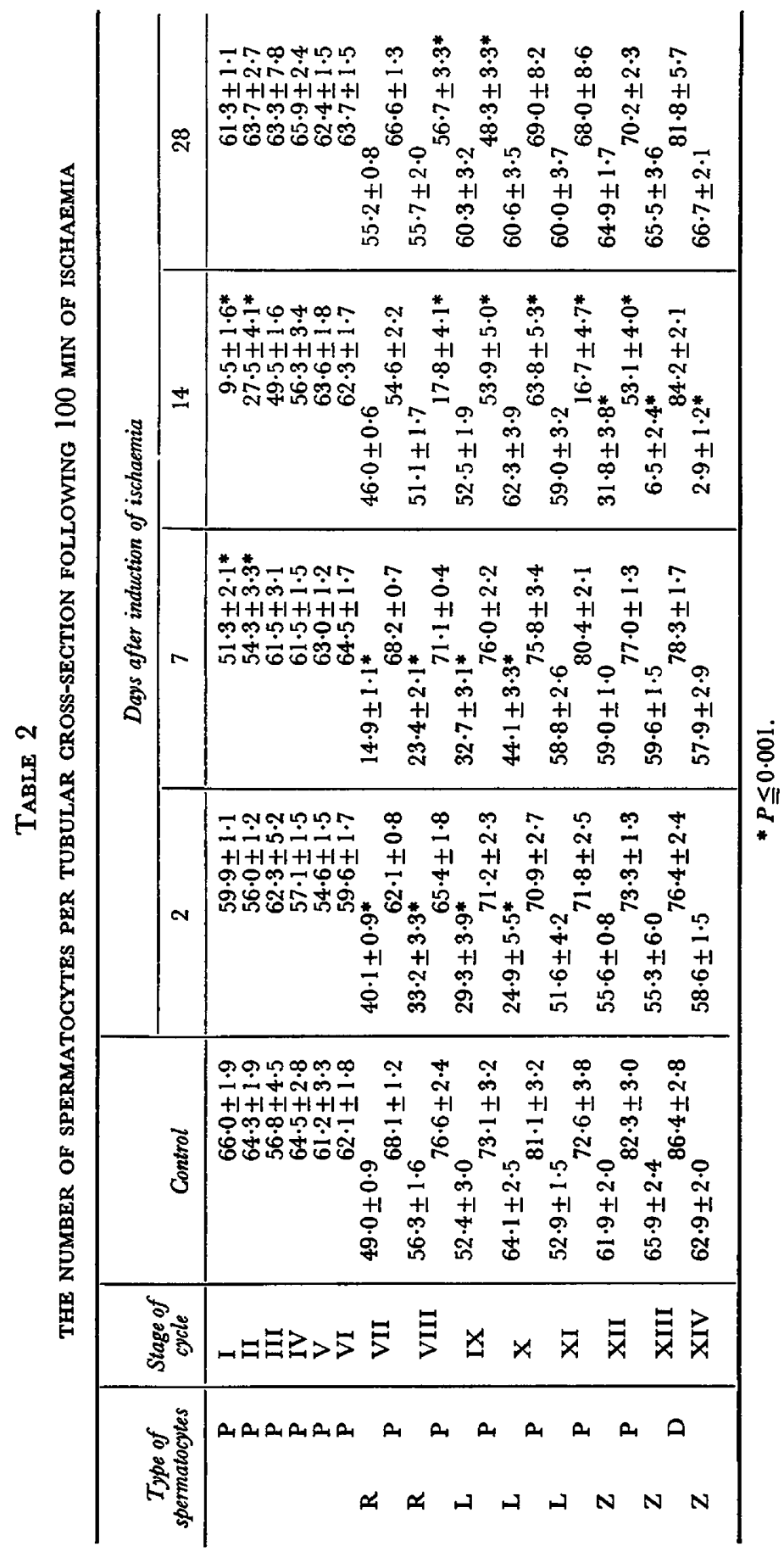


Spermatocytes. Counts of the primary spermatocytes are summarized in Table 2. A significant decrease in the number of resting primary spermatocytes was found in stages VII and VIII 2 days and 7 days after the ischaemia. The leptotene spermatocytes were diminished in numbers in stages IX and X at the same time intervals. The zygotene spermatocytes in stages XII, XIII and XIV and the late pachytene spermatocytes in stages VII to XII were diminished 14 days after ischaemia. At the 28-day time interval, the pachytene spermatocytes in stages VIII and IX were significantly diminished in numbers.

Spermatids. The counts of the spermatids (steps 1 to 8) were normal 2, 7 and 14 days after the ischaemia episode. Twenty-eight days after ischaemia, deviations from the control value were noted in spermatids in steps 3,7 and 8 . It should be noted, that at this time interval, numerous abnormal spermatozoa were also observed. The data are summarized in Table 3.

TABLE 3

THE NUMBER OF SPERMATIDS PER TUBULAR GROSS-SECTION FOLLOWING 100 MIN OF ISCHAEMIA

\begin{tabular}{c|c|c|c|c|c|c}
\hline & & & \multicolumn{4}{|c}{ Days after induction of ischaemia } \\
\cline { 4 - 7 } Spermatids & $\begin{array}{c}\text { Stage of } \\
\text { cycle }\end{array}$ & Control & 2 & 7 & 14 & 28 \\
\hline Step 1 & I & $223 \cdot 1 \pm 5 \cdot 7$ & $199 \cdot 1 \pm 12 \cdot 2$ & $210 \cdot 6 \pm 2 \cdot 8$ & $213 \cdot 4 \pm 3 \cdot 9$ & $209 \cdot 7 \pm 3 \cdot 5$ \\
2 & II & $219 \cdot 1 \pm 5 \cdot 8$ & $195 \cdot 3 \pm 3 \cdot 9$ & $220 \cdot 1 \pm 4 \cdot 6$ & $217 \cdot 9 \pm 7 \cdot 2$ & $195 \cdot 5 \pm 6 \cdot 5$ \\
3 & III & $204 \cdot 2 \pm 9 \cdot 7$ & $215 \cdot 7 \pm 11 \cdot 4$ & $217 \cdot 7 \pm 7 \cdot 6$ & $186 \cdot 0 \pm 7 \cdot 0$ & $160 \cdot 0 \pm 19 \cdot 6^{*}$ \\
4 & IV & $215 \cdot 6 \pm 8 \cdot 4$ & $202 \cdot 1 \pm 3 \cdot 6$ & $209 \cdot 8 \pm 6 \cdot 5$ & $219 \cdot 6 \pm 4 \cdot 2$ & $196 \cdot 8 \pm 6 \cdot 2$ \\
5 & V & $216 \cdot 9 \pm 9 \cdot 4$ & $205 \cdot 6 \pm 3 \cdot 6$ & $214 \cdot 2 \pm 4 \cdot 1$ & $213 \cdot 3 \pm 5 \cdot 3$ & $198 \cdot 9 \pm 4 \cdot 4$ \\
6 & VI & $204 \cdot 3 \pm 5 \cdot 4$ & $207 \cdot 9 \pm 6 \cdot 8$ & $218 \cdot 3 \pm 4 \cdot 1$ & $198 \cdot 9 \pm 4 \cdot 9$ & $202 \cdot 9 \pm 4 \cdot 0$ \\
7 & VII & $221 \cdot 0 \pm 3 \cdot 7$ & $201 \cdot 7 \pm 2 \cdot 3$ & $219 \cdot 9 \pm 2 \cdot 2$ & $207 \cdot 1 \pm 2 \cdot 7$ & $152 \cdot 3 \pm 6 \cdot 3 *$ \\
8 & VIII & $222 \cdot 2 \pm 7 \cdot 5$ & $192 \cdot 9 \pm 3 \cdot 6$ & $220 \cdot 1 \pm 4 \cdot 7$ & $221 \cdot 6 \pm 4 \cdot 7$ & $74 \cdot 1 \pm 7 \cdot 2 *$ \\
\hline
\end{tabular}

${ }^{*} P \leqq 0 \cdot 001$.

\section{DISCUSSION}

The results of this study show that experimentally induced cessation of blood flow to the testes for $100 \mathrm{~min}$ induces a specific response in the seminiferous epithelium. The response is characterized by destruction of specific germinal cell types and the resulting maturation depletion. Using the type of data presented in this paper, back-calculation, based on a knowledge of the duration of the spermatogenic process and the time necessary for the development of specific germinal epithelium cell types (Leblond, Steinberger \& Roosen-Runge, 1963), makes it possible to determine the cell types affected by a noxious agent (Chowdhury \& Steinberger, 1963) such as ischaemia.

Two days after ischaemia, spermatogonia in stages XIV and I to IV were diminished in number. Since it takes about $48 \mathrm{hr}$ for spermatogonia in stage XII to reach stage XIV, the cells in stage XIV 2 days after ischaemia were in stage XII at the time of ischaemia. Thus, the diminution of spermatogonia in stage XIV actually reflected damage to spermatogonia in stage XII. Similar calculations for type A spermatogonia in stages I to IV and type B spermatogonia in stage $\mathrm{V}$ indicate that type A spermatogonia in stage XIV and some 
intermediate type A spermatogonia were affected by the ischaemia. The only other change in the number of germinal cells observed 2 days after ischaemia was a marked decrease in resting spermatocytes and leptotene spermatogonia in stages IX and X. Back-calculation reveals that this diminution must have been a reflection of damage to resting spermatocytes in stage VII and dividing type B spermatogonia in stage VI of spermatogenesis.

The most advanced type of germinal epithelium cells affected 14 days after ischaemia were the pachytene spermatocytes in stage XII of spermatogenesis. Back-calculation reveals that they were resting primary spermatocytes at the time of the ischaemia episode. This finding supports the conclusions drawn from studies of the earlier time intervals. The youngest primary spermatocytes showing a marked decrease in number at this time interval were the zygotene spermatocytes in stage XIII of spermatogenesis; back-calculation reveals that at the time of ischaemia, they were type A spermatogonia in stage XII of spermatogenesis. This finding also supports the conclusions drawn from calculations performed on data 2 and 7 days after the ischaemia.

Examination of data 28 days after ischaemia reveals significant diminution of spermatids in steps 3,7 and 8 of spermiogenesis. Back-calculation places these cells also as type A spermatogonia in stages XII to XIV and resting spermatocytes.

The data reported here demonstrate clearly that changes in counts of cells other than those directly affected by ischaemia were due to a process of maturation depletion. Results of these studies show that ischaemia produces damage to specific types of germinal epithelium cells. Apparently, cells in preparation for division are affected. Mitoses in the germinal epithelium occur in type A spermatogonia in stages IX, XII and XIV, intermediate spermatogonia in stage IV and type B spermatogonia in stage VI. Primarily, cells during those mitotic peaks were affected, except for stage IX. There was also an effect on the resting spermatocytes. The DNA synthesis in preparation for the meiotic division of primary spermatocytes occurs only in the resting spermatocytes. It is possible that the deleterious effect of ischaemia may be related to the DNA synthetic activity in division cycles of cells in mitosis and meiosis.

\section{ACKNOWLEDGMENT}

This work was supported, in part, by Grant AM 05449 from the National Institutes of Health, U.S. Public Health Service.

\section{REFERENCES}

Chowdhury, A. K. \& Steinberger, E. (1963) Selective damage induced by heat to the testicular germinal epithelium of rats. Anat. Rec. 145, 217.

Leblond, G. P., Steinberger, E. \& Roosen-Runge, E. (1963) Spermatogenesis. In: Mechanisms Concerned with Conception. Ed. C. Hartman. Pergamon Press, London.

Oettle, A. G. \& HarRison, R. G. (1952) Histological changes produced in the rat testis by temporary and permanent occlusion of the testicular artery. F. Path. Bact. 64, 273.

STEINBERGer, E. (1962) A quantitative study of the effect of an alkylating agent (triethylenemelamine) on the seminiferous epithelium of rats. F. Reprod. Fert. 3, 250.

Steinberger, E. \& TJIOE, D. Y. (1969) Spermatogenesis in rat testes after experimental ischemia. Fert. Steril. 20, 639 . 